\section{Lignocaine toxicity from topical anaesthesia of airway during awake fibreoptic intubation}

\section{Rudrashish Haldar, Prakhar Gyanesh', Sukhen Samanta ${ }^{2}$}

Awake fibreoptic intubation (AFI) employs a combination of nebulised local anaesthetics (LAs) and nerve and translaryngeal blocks to increase the patient's comfort and acceptability during the procedure. However, application of LA at sites with high absorption potential, carries the hazard of toxicity. We describe a case where a patient undergoing AFI developed lignocaine toxicity during the procedure.

A 48-year-old male patient (ASA I, $65 \mathrm{~kg}$ ) with C1-C2 and $\mathrm{C} 3-\mathrm{C} 4$ prolapsed intervertebral disc (PIVD) with quadriparesis was posted for cervical discectomy and laminectomy. We planned to secure the airway through AFI. After pre-medicating the patient with injection glycopyrrolate $(0.2 \mathrm{mg})$ and injection fentanyl $(100 \mathrm{mcg})$, the patient was nebulised with $4 \mathrm{ml}$ of $4 \%$ lignocaine $(160 \mathrm{mg})$ for 10 minutes. Bilateral superior laryngeal nerves blocks (bilaterally) and translaryngeal block was then administered using $2 \mathrm{ml}$ lignocaine at each point (total $120 \mathrm{mg}$ of lignocaine), after confirming negative aspiration of blood. The fiberscope, mounted with a $8.5 \mathrm{~mm}$ flexomettalic endotracheal tube (ETT), was navigated to reach up to the carina and the ETT was manipulated inside the trachea, within 5 minutes of the blocks. As the tube was being pushed beyond the glottis, the patient complained of dizziness. Within moments he developed involuntary movements, which progressed to frank seizures. As the airway was already secured, we immediately inserted a Guedel's airway to prevent tube biting, and the patient was given a $4 \mathrm{mg}$ bolus of midazolam followed by $250 \mathrm{mg}$ of thiopentone and was hyperventilated with $100 \%$ oxygen. The seizures terminated after 1 minute. No arrhythmias were noted and after the vital signs normalized, the surgery was allowed to proceed. Post-operatively, the patient was kept intubated for overnight ventilation and was extubated safely the next day without any residual neurological deficit.

The patient did not have any previous history of seizures or visible mucosal ulcerations and based on the close temporal association and lack of any other specific reasons, lignocaine toxicity was postulated as the cause. Local absorption of lignocaine can produce toxic effects on the cardiovascular and neurological system (more pronounced in children) when more than recommended dose $(4.5 \mathrm{mg} / \mathrm{kg})$ is administered. ${ }^{[1]}$ Our patient had received a total of $280 \mathrm{mg}$ of lignocaine and assuming that only $8-12 \%$ of the drug reaches the airway due to wastage ${ }^{[2]}$ the total dose administered was definitely within safe limit. Development of toxicity could thus be attributed to factors like tissue vascularity, site and techniques of application. The high vascularity of pharyngeal and tracheal mucosa increases the propensity of rapid LA absorption. Absorption from tracheobronchial tree is rapid and blood levels similar to intravenous administration may result ${ }^{\left[{ }^{[3]}\right.}$ Besides, the use of glycopyrrolate as an anti-sialogogue also increases the risk of elevated plasma levels of LA due to enhanced absorption. ${ }^{[4]}$ Development of toxicity depends upon a critically balanced rate of absorption and metabolism ${ }^{[1]}$ and since hepatic first pass effect is absent, this balance was tilted and toxic levels were attained. Metallic taste and circumoral tingling, which are the initial symptoms of developing toxicity, ${ }^{[5]}$ may have been masked in our case due to the effect of nebulised LA. Clinicians should thus be aware of this probable hazard while performing AFI and should be extra cautious in paediatric, geriatric, hepatically or renally impaired patients and those with mucosal ulceration and low seizure threshold. The so-called 'safe dose' can be misleading in these patients and toxicity might occur at doses much less than the postulated toxic dose. Piercing a vessel and intravascular injection is an inherent risk to all injection procedures. Needle aspiration might not be 'fool proof' if the needle is in a small vein with lesser than the required pressure to cause venous blood flow in the needle hub ${ }^{[6]}$ making intravascular injection a possibility, even with negative aspiration. Repeated aspirations while injecting might prevent some of these complications. Respiratory depression (from sedative premedications) causing hypercarbia and acidosis can also lead to decrease in the threshold of toxicity of LA. ${ }^{[7]}$ Vigilant monitoring for

\footnotetext{
Department of Anaesthesia, Gian Sagar Medical College, Banur, Patiala, Punjab, 'Department of Neuro Anaesthesia and Critical Care, Global Hospital, Chennai, Tamil Nadu, ${ }^{2}$ Department of Anaesthesia and Critical Care, All India Institute of Medical Sciences, Jai Prakash Narayan Apex Trauma Center, New Delhi, India
}

Address for correspondence:

Dr. Rudrashish Haldar, Department of Anaesthesia, Gian Sagar Medical College, Banur, Patiala, Punjab - 140 506, India.

E-mail: rudrashish@yahoo.com 
prompt diagnosis and proper resuscitation equipment at hand for effective management are the keys to avoid disaster.

\section{REFERENCES}

1. Hess PD, Walson PD. Seizures secondary to oral viscous lidoocaine. Ann Emerg Med 1998;17:725-7.

2. Clay MM, Clarke SW. Wastage of drug from nebulisers: A review. J R Soc Med 1987;80:38-9.

3. Adriani J, Zepernick R. Clinical effectiveness of drugs used for topical anesthesia. JAMA 1964;188:711-6.

4. Watanabe H, Lindgren L, Rosenberg P, Randell T. Glycopyr ronium prolongs topical anaesthesia of oral mucosa and enhances absorption of lignocaine. Br J Anaesth 1993;70:94-5.

5. Mulroy MF. Systemic toxicity and cardiotoxicity from local anesthetics: Incidence and preventive measure. Reg Anesth
Pain Med 2002;27:556-61.

6. Goodman BS, Posecion LW, Mallempati S, Bayazitoglu M. Complications and pitfalls of lumbar interlaminar and transforaminal epidural injections. Curr Rev Musculoskelet Med 2008;1:212-22.

7. Adam VN, Markic A, Sakic K, Stojcic EG, Mrsic V, Tonkovic D. Local anaesthetic toxicity. Period Biol 2011;113:141-6.

\begin{tabular}{|l|l|}
\hline \multicolumn{2}{|c|}{ Access this article online } \\
\hline Quick Response Code: & Website: \\
\hline & www.jnaccjournal.org \\
\cline { 2 - 3 } & \\
\hline & DOI: \\
\hline
\end{tabular}

